\title{
Reestruturação metropolitana e dinâmicas imobiliárias: transformações recentes na Região Administrativa Venda Nova de Belo Horizonte-MG
}

\author{
Metropolitan restructuring and real estate dynamics: \\ recent transformations in the Venda Nova Administrative \\ Region of Belo Horizonte - State of Minas Gerais
}

Luciano dos Santos Diniz [l] Maura Pardini Bicudo Véras [II]

\begin{abstract}
Resumo
Este artigo tem como objetivo avaliar o recente processo de reestruturação econômico-espacial implementado pelo Poder Público no Vetor Norte da Região Metropolitana de Belo Horizonte (RMBH) e sua influência na dinâmica imobiliária da Região Administrativa Venda Nova (RAVN). A reestruturação estratégica objetiva a diversificação da base industrial da RMBH, a partir da atração de novos investimentos e do fomento de polos de alta tecnologia. Ambiciona-se, com isso, maior inserção e competitividade dos municípios nos cenários nacional e global. A pesquisa demonstrou que as intervenções procedidas pelo Poder Público incluem grandes obras públicas de infraestrutura e de suporte a serviços, influindo determinantemente na transformação espacial da RAVN, em Belo Horizonte, mediante uma intensa valorização imobiliária e a elitização do espaço.
\end{abstract}

Palavras-chave: região metropolitana; planejamento estratégico; reestruturação econômico-espacial; dinâmicas imobiliárias; Venda Nova.

\begin{abstract}
This study aims to evaluate the recent economic and spatial restructuring process implemented by the government in the North Section of the Metropolitan Region of Belo Horizonte and its influence on the real estate dynamics of the Venda Nova Administrative Region (VNAR). The strategic restructuring aims to diversify the industrial base of the region by attracting investments and creating technopoles. The purpose is to achieve greater integration and competitiveness of municipalities in the national and global scenarios. The study showed that interventions performed by the government include large public works of infrastructure and services support, influencing decisively the spatial transformation of VNAR, in Belo Horizonte, through an intense real estate appreciation and the gentrification of the space.
\end{abstract}

Keywords: metropolitan region; strategic planning; economic and spatial restructuring; real estate dynamics; Venda Nova. 


\section{Introdução}

0 acelerado processo de urbanização das cidades provocou as maiores transformações no cotidiano da população urbana. As cidades passaram a abrigar mais da metade da população mundial, e estima-se que, no ano de 2050, a taxa de urbanização no mundo chegará a $66,4 \%$ (United Nations, 2015). Na cidade capitalista atual, a supremacia do capital financeiro diante do industrial redefine o sentido de espaço, que passa a assumir, também, a condição de produto imobiliário. A urbanização torna-se um negócio rentável, favorecendo que o capital financeiro se aproprie do espaço-mercadoria como locus de realização de investimento produtivo, tendo o capital imobiliário como reprodutor do espaço, enquanto mercadoria consumível individualmente sob a forma de propriedade privada. 0 arranjo espacial da cidade é, então, moldado pelo interesse do capital, que utiliza o solo urbano com o propósito de aumentar as forças produtivas.

Se, por um lado, as cidades são reconhecidas pela potencial riqueza e por sua diversidade econômica, ambiental, política e cultural, por outro, a acelerada urbanização e o modo de estruturação do espaço urbano acabaram gerando imensos contrastes, caracterizados pela fragmentação do espaço, pela concentração de renda e pela exclusão socioterritorial. $A$ cidade torna-se, então, palco do conflito (ricos versus pobres; centro versus periferia; público versus privado), da desordem e de maior expressão da segregação social (Lefebvre, 1999).

Nesse processo, o Estado tem papel determinante com agente indutor da (re)produção da cidade, tanto como regulador do solo urbano, quanto como proprietário fundiário e promotor imobiliário, influindo diretamente na transformação do espaço. Em geral, as diversas políticas e projetos de intervenção espacial, sejam eles públicos ou privados, favorecem a (re)conquista de áreas pelo capital corporativo e especulativo, fomentando o intenso processo de valorização da terra e, em contrapartida, a expulsão/segregação de grande número de moradores pobres em diferentes níveis e regiões das cidades. Para Harvey (1989), tais questões estão relacionadas a um projeto neoliberal, cujos princípios têm orientado a condução dos novos processos de planejamento e gestão estratégicos adotados nas cidades, num cenário de competição interurbana.

No caso do Vetor Norte da Região Metropolitana de Belo Horizonte (RMBH), desde 2005, o Poder Público, em articulação com o capital privado, tem implementado ações destinadas à reestruturação econômico-espacial da região, a partir da implementação de um modelo de gestão estratégica do espaço metropolitano. Tais ações visam potencializar o desenvolvimento dos municípios metropolitanos, consolidando o papel de Belo Horizonte no cenário econômico nacional, além de garantir sua maior competitividade e inserção no mercado global.

As ações modificadoras procedidas pelo Poder Público têm influenciado a valorização da terra urbana no espaço metropolitano e sua apropriação pelo mercado fundiário/imobiliário. Tudo sob a ótica da globalização das cidades e inserção na competitiva "rede" da economia internacional (Gottdiener e Feagin, 1989), o que corrobora a tese da cidade como growth machine (Logan e Molotch, 1987). 
Como resultado, o tecido urbano é moldado pelo interesse do capital, que utiliza o solo urbano com o fim precípuo de garantir o funcionamento da economia global e a circulação, em diferentes escalas, de pessoas e bens (Harvey, 2011). Ou seja, o urbano compreendido não apenas como "locus, mas como forma da expansão capitalista" (Oliveira, 1979, p. 16), em que as iniciativas de (re)produção do ambiente construído têm o fim deliberado de privilegiar a reprodução e a acumulação do capital (Harvey, 2011, 2013).

Nessa perspectiva, o presente artigo retrata o processo de reestruturação econômica espacial desencadeado pelo Poder Público, a partir de 2005, no Vetor Norte da RMBH, buscando identificar os elementos que contribuem para a alteração das dinâmicas imobiliárias da Região Administrativa Venda Nova (RAVN) de Belo Horizonte, para a sua transformação espacial e consequente elitização do seu espaço.

Para tanto, para a identificação dos elementos que caracterizam o processo de reestruturação estratégica, assim como o de (re) produção/consumo do espaço urbano e os instrumentos de gestão urbana, foi utilizada a pesquisa bibliográfica, elaborada a partir de materiais impressos ou em formato eletrônico, de autores nacionais e estrangeiros. Por sua vez, a identificação das alterações ocorridas na infraestrutura urbana do Vetor Norte metropolitano - e, por conseguinte, na RAVN -, baseou-se nos documentos oficiais do Governo do Estado de Minas Gerais e da Prefeitura Municipal de Belo Horizonte.

A pesquisa do mercado imobiliário da RAVN (elevação do valor da terra) ocorreu através da análise da seção de classificados de imóveis do Jornal Estado de Minas, visando a mensurar a quantidade de imóveis residenciais colocados à venda e aqueles destinados à locação, nos meses de janeiro e julho, no período de 2001 a 2013. A delimitação do período analisado guarda estreita relação com a temporalidade das intervenções procedidas pelo Poder Público. A pesquisa englobou 6.727 anúncios de venda/aluguel de imóveis residenciais de características diversas (casa, casa geminada, apartamento tipo e cobertura, barracão e quitinete) localizados na RAVN, a fim de permitir a análise da evolução dos preços de venda e de locação dos imóveis situados na área.

Apesar da desvantagem na utilização dos anúncios de imóveis como fonte de informação do mercado imobiliário da RAVN, por não retratar o preço do imóvel de fato transacionado, dada à eventual diferença entre 0 valor anunciado e o valor de venda ou de locação, parte-se da hipótese de que a evolução dos dois valores (anunciado e transacionado) tenha tendências semelhantes no médio e longo prazo. A utilização dos anúncios de imóveis como fonte de informação do mercado imobiliário é utilizada em países como Áustria, Espanha, EUA, Hungria e Inglaterra, sendo também adotada pela Fundação Instituto de Pesquisas Econômicas - Fipe (2014), para a elaboração de um índice nacional de preços do setor imobiliário.

Importante ressaltar que houve uma limitação nesta pesquisa, representada pela análise da progressão do valor da terra, no período 2001-2013, por intermédio dos índices de arrecadação do Imposto Predial e Territorial Urbano (IPTU) e do Imposto sobre a Transmissão de Bens Imóveis (ITBI) da Prefeitura Municipal de Belo Horizonte. A "Planta de Valores 
Genéricos", elaborada no ano de 2003 e atualmente utilizada como base para a tributação dos impostos imobiliários, apresenta uma grande defasagem em relação ao valor de mercado dos imóveis, impedindo a avaliação da real variação dos valores dos bens imóveis situados na área de estudo (Gomes, 2008; Almeida, 2009).

A identificação das alterações ocorridas na infraestrutura urbana da RAVN, na tipologia dos imóveis (residenciais e comerciais) e respectivos padrões construtivos, baseou-se nos documentos oficiais da Prefeitura Municipal de Belo Horizonte, disponibilizados pela Secretaria Municipal Adjunta de Arrecadação (Smaar).

0 trabalho está estruturado em cinco partes, além da presente introdução. $\mathrm{Na}$ primeira, abordam-se algumas perspectivas teóricas de apreensão do espaço urbano que favorecem a construção e a análise das complexidades imanentes ao objeto de estudo. Em seguida, discutem-se questões relacionadas à (re)produção do espaço urbano e os mecanismos de fomento e apropriação da renda da terra urbana nas cidades capitalistas hodiernas. Na terceira parte, tratam-se questões relacionadas à configuração socioespacial da cidade de Belo Horizonte e a sua relação de interdependência com os municípios adjacentes. $\mathrm{Na}$ quarta, ressaltam-se os planos e as ações estratégicas adotados na reestruturação econômico-espacial do Vetor Norte da Região Metropolitana e suas implicações para as dinâmicas imobiliárias da RAVN e as recentes transformações na paisagem da referida região. Por último, e em apertada síntese, são apresentadas as considerações finais do trabalho.

\section{Considerações sobre a (re)produção da cidade capitalista}

No contexto das cidades, a enorme concentração de pessoas e a utilização da terra para os mais diversos fins favorecem uma disputa pelo uso do solo. Para alguns, lugares constituem local de residência ou de produção; para outros, lugares representam uma mercadoria para comprar, vender ou alugar para outra pessoa (Logan e Molotch, 1987). 0 espaço produzido, sob o viés da industrialização, torna-se mercadoria, assim como os demais produtos criados pela produção capitalista, facultando a realização da propriedade privada do solo urbano no conjunto da riqueza social.

O sistema capitalista, atraído pelas vantagens da aglomeração e pela socialização das condições gerais da produção, apropria-se do espaço citadino como condição e meio para a realização concreta do ciclo produtivo, em seus momentos de produção, distribuição, circulação, troca, consumo de mercadorias e, por conseguinte, realização do lucro (Topalov, 1979). As cidades são vistas, então, como growth machines, organizadas como empresas dedicadas ao aumento dos níveis de renda, mediante a intensificação do uso da terra (Logan e Molotch, 1987).

Desse modo, a valorização da terra está intrinsecamente relacionada às vantagens e oportunidades que a sua localização pode propiciar ao comprador/usuário, tais como: infraestrutura (energia, transporte público, água e demais serviços urbanos) e fácil acesso ao comércio, à distribuição de bens, entre outras. 
Logo, 0 acesso às regiões privilegiadas com infraestrutura e prestação de serviços fica restrito aos grupos de maior renda, devido à excessiva valorização (elitização) do solo, relegando a população mais pobre às zonas mais mal servidas (Singer, 1979).

De acordo com Limonad (2011), as transformações socioespaciais resultantes da distribuição das atividades produtivas e da população no espaço citadino decorreriam tanto da atuação do Estado e de distintos capitais empresariais, quanto das estratégias de localização e distribuição da força de trabalho (variantes de classes sociais da população), conforme a conjuntura e as especificidades de cada lugar.

Nas últimas décadas do século XX, a profunda recessão de 1973, agravada pelo choque do petróleo, provocou substanciais alterações no capitalismo de regime fordista, principiando um conturbado período de reestruturação econômica e de reajustamento social e político. As mudanças representavam os primeiros indícios de passagem a um novo regime de acumulação - denominado "acumulação flexível" (Harvey, 2011). Como consequência, um novo espaço constitui-se à escala mundial (neocapitalismo), apoiando-se nas redes financeiras, da informação e da circulação (Lefebvre, 2000). Trata-se da cidade capitalista no atual período monopolista, da denominada acumulação flexível, enquanto produto direto das relações sociais de produção, da reestruturação produtiva, do avanço tecnológico e informacional, da globalização, dos fluxos planetários de pessoas, informações, mercadorias e dinheiro (Santos, 1985; Harvey, 2011; Borja e Castells, 1997; Véras, 2010).

0 tecido urbano é, então, moldado para permitir o funcionamento da economia global e a circulação, em diferentes escalas, de objetos (dinheiro, maquinário, matérias-primas, mercadorias, bens de consumo) e de sujeitos (na qualidade de trabalhadores e, também, como migrantes, turistas, viajantes, consumidores), enquanto representantes da dimensão físico-material (Rodrigues, 2010).

Nesse contexto, a velocidade da informação sobre os mercados internacionais e de resiliência das cidades diante deles, associados à flexibilidade das estruturas produtivas e comerciais e à capacidade de inserir-se em redes, são determinantes para a atratividade da cidade e o seu sucesso (ou fracasso) na economia global, " muito mais do que as posições adquiridas no passado, o capital acumulado, as riquezas naturais ou a situação geográfica" (Castells e Borja, 1996, p. 153).

Inspirados no exemplo norte-americano de Silicon Valley, Castells e Hall (1994) afirmam que a estrutura de tais cidades é influenciada pela ação simultânea de três processos inter-relacionados: (1) a revolução tecnológica baseada na tecnologia da informação (incluindo a engenharia genética); (2) a formação de uma economia mundial - englobando o capital, a gestão, o trabalho, a tecnologia, a informação e os mercados -, cujas produtividade e competitividade decorrem da geração de novos conhecimentos e do acesso e processamento adequado da informação; (3) o surgimento da produção e gestão informacional, caracterizada pela geração de novos conhecimentos e pelo acesso ao processamento adequado da informação.

Castells e Hall (ibid.) salientam, contudo, que o êxito de tais polos da economia global está condicionado à existência de apoio das autoridades locais, regionais e nacionais; 
à presença de instituições dedicadas à investigação e à informação; à concessão de incentivos fiscais e financeiros; à disponibilidade de terrenos industriais; à disponibilidade de mão de obra qualificada (profissionais e técnicos de qualidade); à existência de sistemas de transporte (autoestradas, porto, aeroporto internacional) e de comunicação adequados; à imagem e à qualidade urbana do local (atividades de entretenimento, lazer, cultura, consumo e sociabilidades); à flexibilidade burocrática. Todos esses fatores constituem importantes atrativos para os investidores e, por conseguinte, para o êxito do parque tecnológico (a ser) implantado na cidade (Castells e Borja, 1996; Borja e Castells, 1997; Savage, Warde e Ward, 2003).

Conforme Sassen (1998), na nova economia de escala mundial, intensifica-se a competição entre cidades, centrais e periféricas, por recursos e atividades que englobam investimentos estrangeiros, matrizes e instituições internacionais ou turismo, entre outros, como forma de garantir o acesso a mercados cada vez mais globais.

Com base nessa perspectiva, o Estado tem papel determinante (senão o principal) como agente indutor da (re)produção da cidade, tanto como regulador do solo urbano (alterando as leis de zoneamento, parcelamento, uso e ocupação do solo; instalando equipamentos públicos e infraestrutura urbana; direcionando a alocação de investimentos orçamentários; atuando diretamente na realização das operações urbanas), quanto como proprietário fundiário e promotor imobiliário, influindo diretamente na transformação do espaço urbano (oferta de serviços, de infraestrutura urbana, de equipamentos de consumo coletivo).

Em vista disso, sempre que o capital privado implementa vantagens locacionais por meio de empreendimentos imobiliários, como shoppings centers e similares, ou o Poder Público dota determinada região de infraestrutura e de serviços públicos, ele atrai para essa área demandas de empresas e moradores que anteriormente, pela ausência da infraestrutura ou dos serviços em questão, davam preferência a outras zonas da cidade. Tais demandas, por certo, estão preparadas a pagar pelo uso do solo, mediante compra ou aluguel, preços superiores àqueles pagos pelas demandas que se dirigiam à mesma região quando ainda não estava provida da infraestrutura ou dos serviços públicos. Além disso, tais intervenções promovem perversos processos de "limpeza social", com expulsão da população vulnerável. Haja vista que 0 acesso às regiões mais bem servidas de infraestruturas e serviços se restringe às camadas mais abastadas da população, devido ao "enobrecimento" do solo (Singer, 1979).

Diante da mudança dos tipos de uso do solo, abrem-se novos caminhos de desenvolvimento para a absorção do excedente de capital, em que as ondas de inovação tecnológica e organizacional promovem drásticas transformações na paisagem urbana, implicando episódios de destruição criativa, nos quais um conjunto de formas dominantes (desvalorizado) é sucedido por outro (valorizado), originando novas geografias, novos espaços para a acumulação (Harvey, 2005 e 2011). 


\section{Empreendedorismo urbano e a (re)produção espacial das cidades}

Na atual fase do capitalismo, a (re)produção dos espaços urbanos volta-se fundamentalmente para a atração de investimentos financeiros, seja através da construção de centros comerciais, de negócios ou de tecnologia, seja pela implementação de empreendimentos destinados ao turismo e ao lazer (como salões de convenção, arenas esportivas, shopping centers, centros culturais, entre outros), tudo sob a ótica da globalização das cidades.

Conforme Gottdiener e Feagin (1989), as cidades vêm implementando esquemas de reestruturação, subsidiados com recursos públicos e mediante a intervenção do Estado. A partir de ambiciosos projetos estratégicos, o Poder Público atua no sentido de flexibilizar suas estruturas produtivas e comerciais, atrair investimentos, promover o turismo e a realização de grandes eventos, capacitando-as à inserção nas redes da economia global e possibilitando-lhes maior competitividade nacional e internacional (Castells e Borja, 1996). Ao que parece, as cidades vendem-se freneticamente, mediante a afirmação de sua competitividade e respectivas vantagens locacionais (Ward, 2004).

Tais aspectos, segundo Harvey (1989), constituem o denominado empreendedorismo urbano, em que as cidades, na condição de mercadorias, são adequadas à ordem econômica mundial. Os planos de gestão estratégica surgem como importantes instrumentos do planejamento urbano atual, destinados a fomentar o crescimento econômico e o desenvolvimento da cidade. A adoção de práticas de city marketing busca promover uma imagem de cidade que propicie a projeção dos seus principais "produtos" no exterior (como turismo, cultura, qualidade de vida, serviços avançados, entre outros), incrementando sua "venda" no competitivo mercado internacional, mediante a captação de investimentos, a atração de turistas e a criação de empregos (Borja e Castells, 1997; Kavaratzis, 2009).

Nessa nova dinâmica, as políticas urbanas do city marketing são orientadas à criação ou ao atendimento das necessidades do público consumidor - empresas, turistas e os próprios moradores (Kotler, Haider e Rein, 1993). Os planos estratégicos propõem políticas integradas de longo prazo, destinadas à execução de grandes projetos que conciliam medidas de crescimento econômico e desenvolvimento urbano, com tomadas de decisões de riscos, formulação de indicadores de seguimento e envolvimento de agentes públicos e privados ao longo do processo (Sánchez, 1999; Arantes, 2002; Vainer, 2002; Novais et al., 2007).

Há um consenso geral em todo o mundo capitalista avançado de que os benefícios positivos são obtidos pelas cidades que adotam um comportamento empreendedor em relação ao desenvolvimento econômico. As estratégias de desenvolvimento urbano variam de cidade para cidade, baseadas na realidade, nos recursos específicos (naturais, humanos, locacionais), no objetivo e no público a atingir (Harvey, 1989 e 2005).

Segundo Harvey (ibid.), há quatro estratégias relativas ao empreendedorismo urbano, as quais, todavia, não se excluem entre si. A primeira enfoca o fomento de vantagens específicas destinadas à produção de bens e serviços, mediante a exploração de recursos 
naturais ou da localização estratégica; a criação, através de "parceria público-privada" (PPP), de infraestruturas físicas (como transportes, comunicações, instalações aeroportuárias) e sociais (como educação, ciência e tecnologia, cultura) que fortaleçam a base econômica da região; o estímulo à criação de novos produtos e tecnologias; a redução dos custos locais (pela concessão de subsídios, renúncias fiscais, crédito barato); a qualidade, quantidade e custos da oferta local de mão de obra.

A segunda estratégia diz respeito à divisão espacial de consumo, em que a região urbana busca melhorar sua posição competitiva enfocando a qualidade de vida, o turismo, a cultura e o lazer, como forma de atrair maior público consumidor (turistas). A terceira opção compreende as atividades de controle e de comando referentes às altas finanças, ao governo, à produção de conhecimento, à coleta e ao processamento de informações. Por fim, a quarta estratégia relaciona-se aos mecanismos redistributivos de superávits pelos governos centrais, como forma de sobrevivência urbana, em um cenário de barreiras espaciais reduzidas e de acirramento da concorrência interurbana.

Harvey (2005) salienta, no entanto, que, devido ao caráter especulativo dos investimentos estratégicos, o êxito das ações destinadas à "venda" de uma cidade como local propício à realização de uma determinada atividade depende, em primeiro lugar, da criação de uma imagem urbana atraente. Seguindo a mesma lógica do marketing empresarial, a construção de uma "marca" para a cidade consiste, então, no diagnóstico das potencialidades econômicas e sociais da localidade, diante das demandas das empresas e dos setores alvos, seguido da avaliação dos aspectos positivos e negativos que deverão ser destacados ou modificados na divulgação da imagem da cidade (Compans, 1999).

Mas, de acordo com tal perspectiva, deve-se reconhecer que a versão contemporânea do empreendedorismo urbano pode ocultar os contrastes eventualmente existentes entre o aparente vigor dos projetos de regeneração de economias urbanas e os problemas sociais e econômicos subjacentes - sobretudo nas cidades brasileiras. Tal paradoxo, em muitas cidades, acaba favorecendo um caráter geográfico dual, exteriorizado pela regeneração de uma área decadente e um mar circundante de crescente pobreza (Harvey, 2005), em que as políticas públicas se mostram pouco sensíveis às necessidades básicas dos cidadãos (provisão de moradia, saúde, educação, emprego, melhores condições de trabalho, espaços de convivência social).

A disseminação das estratégias de desenvolvimento local, para garantir maior atratividade das cidades, implica o enobrecimento das regiões que passam por intervenções urbanísticas e ambientais (ibid.). Em seu objetivo de produzir um espaço urbano homogêneo e atrativo para o capital internacional, as intervenções urbanísticas, muitas vezes, acabam por promover uma impiedosa limpeza social - via expropriação imobiliária, reassentamentos forçados e expulsão da população autóctone.

A (re)produção do espaço - aqui, concebido como terra nua - dá-se com o objetivo de garantir a reprodução ampliada do capital, sem a menor consideração com a história, a memória, as pessoas e as relações sociais nele produzidas ao longo do tempo (Carvalho, 2004). Como aponta Santos (2007, pp. 63-64), "a lei é a do processo produtivo, cujos resultados 
Figura 1 - Regionais adminstrativas de Belo Horizonte

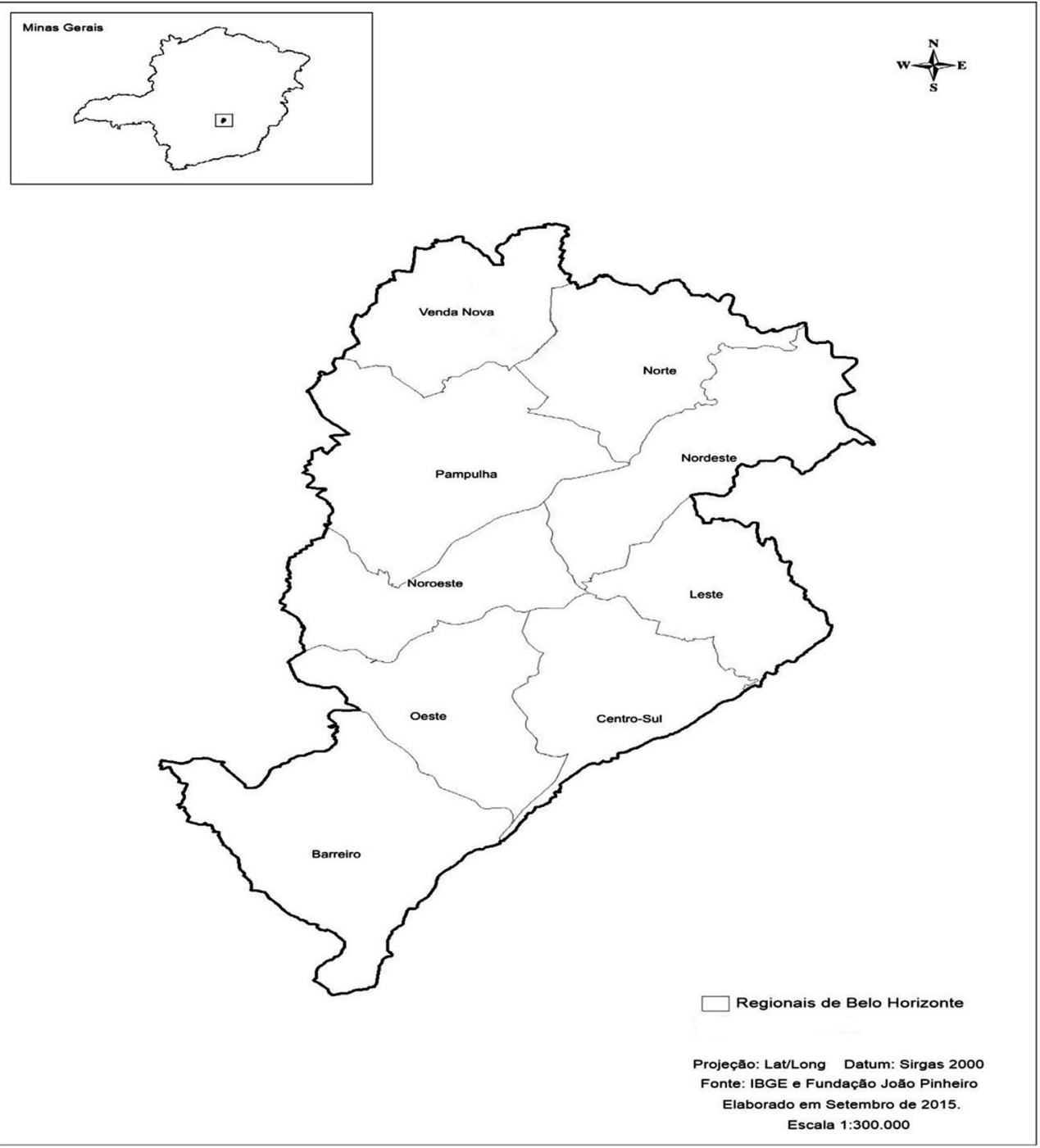

Fonte: Fundação João Pinheiro, 2015. 
ofendem, expulsam e desenraizam as pessoas, e não a lei que assegure o direito à cidade ou, ao menos, o direito ao entorno".

\section{Belo Horizonte e a estruturação do espaço metropolitano}

Inaugurada em 12 de dezembro de 1897, a cidade de Belo Horizonte foi concebida como a primeira cidade inteiramente planejada do País, com o fim de tornar-se a capital do estado de Minas Gerais. Desde o início, o desenvolvimento da cidade foi marcado pela observância das diretrizes traçadas na sua planta básica apenas na área delimitada como urbana - concentradora da infraestrutura, dos serviços e do comércio. Fora da zona urbana, o crescimento ocorreu de forma mais espontânea e desorganizada, sobretudo a partir das décadas de 1940 e 1950, quando a expansão de Belo Horizonte passou a ser impulsionada pelo processo de industrialização e pelo incremento da ocupação periférica, com uma crescente relação de interdependência (econômica, social) entre a capital e os municípios ao redor (Villaça, 1998; Andrade, 2009; Costa, 2009).

Para Villaça (1998, p. 114), Belo Horizonte é assim caracterizada: (1) uma metrópole interiorana, "que dispõe de área para expansão em todas as direções: 360 graus"; (2) uma cidade que, no início de sua expansão, é dividida ao meio pelo rio Arrudas e pela ferrovia que se aloja junto a ele. "A barreira divide o espaço urbano em duas partes" - o "lado de cá" (no qual se localiza a área central) e o "lado de lá" (oposto à área central) -, cuja diferença nos custos e tempo de deslocamentos à área central torna um espaço mais vantajoso que o outro; (3) em função dessa vantagem, o lado que compreende a área central tende, a princípio, a abrigar a maior parcela do crescimento urbano. Embora, no caso de Belo Horizonte, isso não tenha ocorrido como planejado; (4) as classes mais abastadas tendem a se concentrar no "lado de cá", mais vantajoso (região centro-sul). Contudo, não exclusivamente, posto que há, também, camadas de baixa renda nesse lado. 0 "lado de lá", a grande região norte, onde está localizada a RAVN, "passa a ficar 'fora de mão' e os bairros de alta renda tendem a não vingar ali, como a região de (sic) Pampulha".

A partir de 1956, são identificados seis eixos de expansão em Belo Horizonte: Sul, Sudoeste, Oeste, Leste, Norte-Central e Norte, evidenciando-se a configuração polarizada "norte versus sul", devido à concentração das camadas mais ricas da população na região sul e, no extremo oposto, a ocupação pela população de baixa renda, em áreas de limitada infraestrutura e qualidade na prestação de serviços (Andrade, 2009; Costa e Mendonça, 2010). 0 crescimento espraiado da cidade desencadeou, mais tarde, o processo de metropolização da região e ensejou, em meados de 1973, a instituição da Região Metropolitana de Belo Horizonte (RMBH).

Atualmente, Belo Horizonte compreende um território de 331,0 km², o qual é subdividido em nove Regiões Administrativas (Figura 1): Barreiro; Centro-Sul; Leste; Oeste; Nordeste; Noroeste; Norte; Pampulha e Venda Nova, com o propósito de facilitar o planejamento e a gestão da cidade.

Localizada no Eixo Norte do município de Belo Horizonte, a Região Administrativa 
Venda Nova (RAVN) possui uma população de 265.388 habitantes, distribuída nos 28,316 km² de sua extensão territorial, caracterizando uma densidade demográfica de 9.259,1 hab./km² (IBGE, 2014).

A ocupação do Eixo Norte do Município caracterizou-se pelo pouco desenvolvimento e pela população de baixa renda em assentamentos populares, sobretudo nas Regiões Administrativas Norte e Venda Nova. Do mesmo modo, no decorrer do processo de metropolização, verificou-se uma intensa concentração dos segmentos mais pobres da população em alguns dos municípios localizados no denominado Vetor Norte da RMBH, isto é, Pedro Leopoldo, Ribeirão das Neves, Santa Luzia, Vespasiano, entre outros. Apenas em Lagoa Santa se observa a implantação de sítios de lazer e condomínios fechados de alta renda (Minas Gerais, 2006; Prefeitura Municipal de Belo Horizonte, 2008; Souza e Brito, 2008; Andrade, 2009; Costa, 2009; Diniz e Monte-Mór, 2012). De forma que, na estruturação do Vetor Norte da RMBH, contrastam regiões com assentamentos voltados para as camadas mais abastadas da população e outros voltados para os estratos mais baixos de renda, em que o planejado e o não planejado, o legal e o ilegal, alternam-se na estruturação do seu espaço (Cardoso, 2003; Kamel, 2007; Andrade, 2009).

\section{Reestruturação do Vetor Norte da RMBH e os impactos na RAVN}

Na década de 2000, em contraposição à redução de investimentos públicos e privados das décadas anteriores, processou-se uma série de intervenções na estruturação do espaço da RMBH. A partir da constituição de um novo arranjo institucional de gestão metropolitana, buscou-se alavancar a retomada do crescimento econômico e reorganização produtiva da região. Os estudos desenvolvidos para a elaboração do "Plano Diretor de Desenvolvimento Integrado" (PDDI) da RMBH permitiram identificar os problemas metropolitanos e a proposição de políticas e programas a serem implementados pelo governo do Estado, com a colaboração e integração dos municípios e da participação da sociedade civil, tendo como referencial temporal de médio prazo o ano de 2023 e de longo prazo o ano de 2050 (Minas Gerais, 2011). O PDDI insere-se no contexto político-institucional mais amplo do processo de implantação e consolidação do novo sistema de planejamento e gestão metropolitanos, ${ }^{1}$ articulando e integrando as várias propostas, projetos e programas já existentes no âmbito do Governo do Estado, tais como o Plano Mineiro de Desenvolvimento Integrado (PMDI) ${ }^{2}$ (Minas Gerais, 2007 e 2016), o Programa de Desenvolvimento e Gestão da Região Metropolitana de Belo Horizonte - Plano de Ações Imediatas para o Vetor Norte ${ }^{3}$ (Minas Gerais, 2008) e o Plano Macroestrutural do Vetor Norte da Região Metropolitana de Belo Horizonte ${ }^{4}$ (Minas Gerais, 2010).

A agenda estratégica do Estado pretende a construção de um ambiente econômico competitivo, estável, seguro ao investidor e atrativo ao desenvolvimento de negócios (Minas Gerais, 2007), tendo como principal diretriz a construção de um processo de planejamento participativo, integrado e perene (Costa, 2009; Diniz e Monte-Mór, 2012). 
Por sua vez, o "Plano Estratégico de Belo Horizonte 2030 - A cidade que queremos" (PEBH), de 2009, está alinhado com os planos estratégicos, programas e projetos de desenvolvimento socioeconômico elaborados pelo Estado, no contexto metropolitano. De acordo com o PEBH, a reconfiguração de Belo Horizonte, com o desenvolvimento de novos polos de dinamismo econômico, envolve a atração de indústrias de base tecnológica; a produção de produtos e a oferta de serviços com alto valor agregado; o desenvolvimento de serviços associados a polos turísticos (Prefeitura Municipal de Belo Horizonte, 2009).

Os planos de desenvolvimento econômico adotados pelos Poderes Públicos do Estado e do Município de Belo Horizonte partem das mesmas premissas e evidenciam as práticas de empreendedorismo urbano na condução dos novos processos de planejamento e gestão estratégicos das regiões. 0 "planejar", aqui, envolve a criação de uma "imagem" vendável da cidade, objetivando a atração de usuários solventes; horizontes de longo prazo e sob condições de incerteza; oportunidades e ameaças; forças e fraquezas; estratégias para diferentes cenários ("melhor futuro" ou de "superação de adversidades"); metas e resultados; PPPs; governança urbana; stakeholders; inserção como metrópole/cidade global; a transição do modo de produção na direção de segmentos que privilegiem a geração de produtos ou serviços intensivos em conhecimento e inovação; diminuição de custos e aumento de lucros (Minas Gerais, 2007; Prefeitura Municipal de Belo Horizonte, 2009).

Dentre as ações reestruturantes implementadas na RMBH, interessa-nos especialmente a série de programas e projetos voltados para atrair o interesse/investimento privado e estimular o desenvolvimento do Vetor Norte da $\mathrm{RMBH}$. A reestruturação produtiva do Vetor Norte da RMBH objetiva a diversificação de sua base industrial e a criação de polos de alta tecnologia, a partir da atração de indústrias de ponta, nacionais e internacionais, em aeronáutica, biotecnologia, semicondutores, informação, microeletrônica, softwares, farmacoquímica, etc., que utilizarão a infraestrutura proporcionada pelo Aeroporto Internacional Tancredo Neves (AITN), para a circulação aérea dos produtos. A produção de mercadorias de maior valor agregado em setores de tecnologia de ponta visa intensificar sua capacidade de polarização regional, favorecendo, também, sua internacionalização competitiva no mercado global (Minas Gerais, 2007 e 2010; Costa e Magalhães, 2011).

0 desenvolvimento do setor de alta tecnologia na região está atrelado a um conjunto de fatores que condicionam o êxito do plano estratégico, tais como: infraestrutura urbana (transporte, comunicação, energia); serviços especializados; presença de instituições de pesquisa; ampla concessão de incentivos fiscais e financeiros; qualidade de vida urbana e ambiental, atividades de entretenimento, lazer, cultura e consumo (Costa e Magalhães, 2011). Ou seja, requisitos fundamentais para a atração de investimentos e de uma classe trabalhadora altamente qualificada, cultural e economicamente. Haja vista que as decisões de investimento não estão associadas apenas a fatores institucionais e à competitividade da economia, sendo, também, influenciadas pela oferta de um ambiente propício à convivência social e com qualidade de vida, sobretudo se considerados o estilo de vida, gostos e 
Figura 2 - Grandes equipamentos do Vetor Norte da RMBH

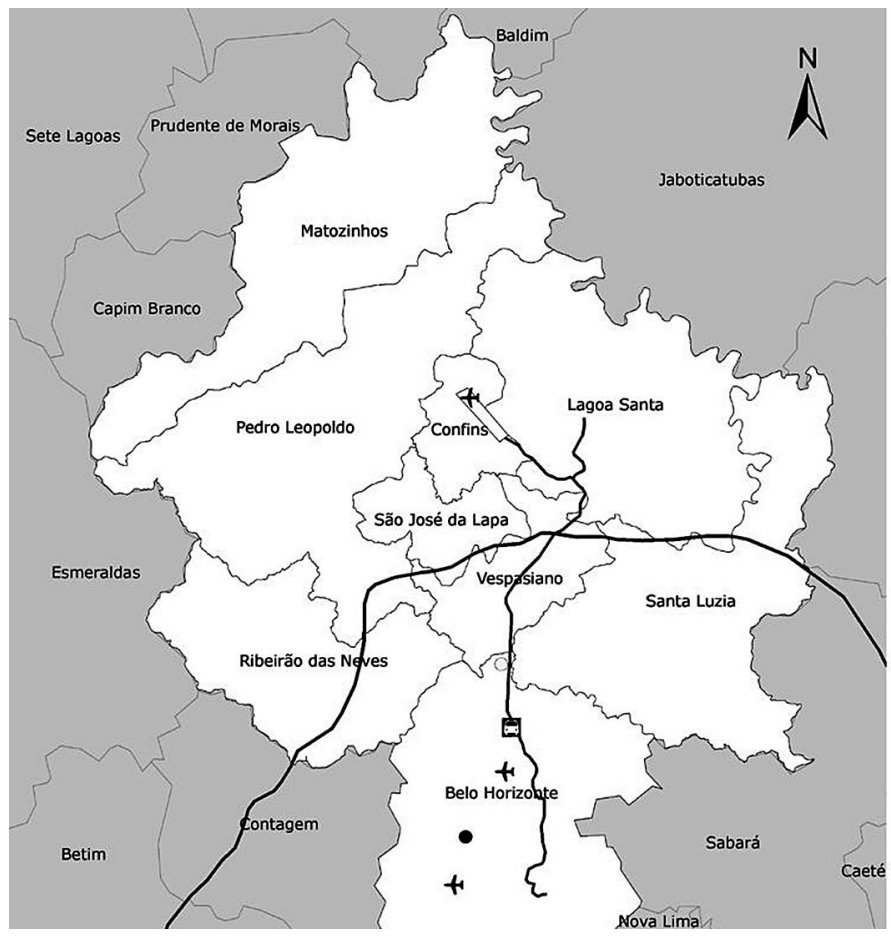

Vetor Norte da Região

Metropolitana de Belo Horizonte

Grandes Equipamentos

\section{Legenda:}

+ Aeroportos

- BHTEC

Estação Vilarinho

- Centro Administrativo

- Rodoanel Aeroporto Confins Municipios Limítofes Municípios Vetor Norte

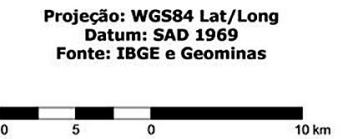

Fonte: Sathler et al. (2011, p. 14).

práticas de consumo de uma classe social mais abastada.

Nesse processo, o Poder Público tem atuado como fomentador e articulador da expansão urbana, assumindo a implantação das obras que induzem a constituição de novos empreendimentos e o desenvolvimento de economias de localização e aglomeração. 0 plano estratégico de desenvolvimento do Vetor Norte da RMBH está ancorado na capacidade estruturante de quatro "grandes projetos urbanos" 5 (Figura 2): (1) AITN - Hub internacional de transporte de passageiros e cargas e primeiro aeroporto-indústria do País, localizado no município de Confins. A caracterização do AITN como aeroporto-indústria confere às empresas de alta tecnologia, instaladas na sua área de influência, a isenção de impostos federais e estaduais, tanto para a importação de componentes como para a exportação de produtos finais de alto valor agregado, tornando-as mais competitivas no mercado global; (2) a "Linha Verde" - projeto de ampliação e modernização da via MG-10, que conecta o centro da capital diretamente ao AITN; (3) o Centro Administrativo (CAMG) - instalado na Região 
Administrativa Venda Nova, às margens da "Linha Verde", atualmente abriga os órgãos da administração direta e parte da administração indireta do Governo do Estado. A instalação do CAMG numa área marcada pela ocupação marginalizada altera, simbolicamente, o locus da centralidade do poder político do Estado, potencializando o seu desenvolvimento e sua transformação socioespacial; e (4) o Anel Viário de Contorno Norte (Rodoanel) - conjuntamente à "Linha Verde" - forma a principal estrutura sobre a qual o design de toda a rede de transporte metropolitana é baseado. 0 Rodoanel interligará o AITN às principais áreas industriais da RMBH, favorecendo as atividades da plataforma logística de desenvolvimento industrial, além de melhorar a acessibilidade de Belo Horizonte às cidades de São Paulo, Brasília, Vitória e Rio de Janeiro (Minas Gerais, 2006, 2008, 2010 e 2011; Prefeitura Municipal de Belo Horizonte, 2008; Costa, 2009; Costa e MagaIhães, 2011; Diniz e Monte-Mór, 2012).

Ao favorecerem a reprodução do espaço metropolitano, esses quatro megaprojetos urbanos contribuem para a criação de externalidades positivas e novas frentes de valorização do capital, como a implantação do BH-TEC parque tecnológico, em Belo Horizonte, voltado à realização de atividades de $\mathrm{P} \& \mathrm{D}$, para a produção de bens e serviços inovadores e de alta tecnologia. Assim como a instalação do Polo Industrial Tecnológico em Vespasiano (primeiro em nanotecnologia da América do Sul), do Polo Industrial de Microeletrônica e do Centro de Tecnologia e Capacitação Aeroespacial em Lagoa Santa, todos direcionados à fabricação de produtos de alto valor agregado. Tais projetos, além de estimularem vultosos aportes de recursos públicos/privados, impulsionam o desenvolvimento urbano da região, modificando os padrões de uso, ocupação, sociais e econômicos nas áreas do entorno, revertendo o processo de ocupação de população de baixa renda que marca aquela periferia (Minas Gerais, 2006; Prefeitura Municipal de Belo Horizonte, 2008; Costa e Mendonça, 2010).

Na esteira do AITN, do CAMG, da "Linha Verde" e do Rodoanel, ocorre uma significativa valorização fundiária no Vetor Norte da RMBH e, igualmente, na RAVN, estimulando a atuação dos agentes econômicos que veem no novo arranjo territorial uma forma de ampliar as possibilidades de investimento do capital (inclusive de caráter especulativo) e a extração de renda adicional.

Verificam-se, então, uma intensa verticalização nas áreas mais bem servidas de infraestrutura e mais próximas do CAMG e a intensificação do número de "enclaves fortificados", compostos por grandes condomínios residenciais fechados, com estruturas destinadas ao consumo e ao lazer, voltados para as classes mais abastadas (Salgueiro, 1998; Caldeira, 2000). Nesse sentido, parcelas consideráveis da população com maior poder aquisitivo vêm se estabelecendo em condomínios suburbanos estrategicamente localizados nos municípios que compõem a área de influência desses empreendimentos, como Jaboticatubas, Lagoa Santa, Vespasiano, Matozinhos e Santa Luzia, favorecidos pela melhora na acessibilidade proporcionada pela "Linha Verde" e pelas expectativas de crescimento econômico da região.

Apesar de não haver previsão normativa, em Lei Federal, para os denominados "condomínios horizontais", os planos diretores municipais e as leis de ocupação e uso do solo estabelecem parâmetros urbanísticos que tendem a 
determinar zoneamentos municipais permissivos a tais empreendimentos. 0 incentivo decorre, muitas vezes, da possibilidade de aumentar a arrecadação municipal do IPTU, bem como de atrair população com maior poder aquisitivo, com potencial para transformar a dinâmica demográfica da localidade e favorecer o seu desenvolvimento - novos fluxos de pessoas, de mercadorias, de serviços e de capital.

Como ressaltado por Rolnik (1997, p. 47), a lei, ao definir que num determinado espaço pode ocorrer somente um certo padrão, opera o milagre de desenhar uma muralha invisível e, ao mesmo tempo, criar uma mercadoria exclusiva no mercado de terras e imóveis.

Embora alguns planos diretores municipais contemplem a delimitação de zonas especiais de interesse social (Zeis), para a implementação de programas de habitação popular e regularização fundiária, verifica-se a intenção velada de inibir a imigração da população de baixa renda, mediante a definição de altos valores de áreas mínimas de lotes. 0 município de Santa Luzia, por exemplo, proíbe a constituição de parcelamentos com lotes de área inferior a $200 \mathrm{~m}^{2}$, exceto nas zonas caracterizadas como Zeis. Em contrapartida, incentiva a implantação de parcelamentos com lotes de áreas superiores a $1.000 \mathrm{~m}^{2}$, para possibilitar a destinação de terrenos a condomínios residenciais de alta renda. 0 mesmo expediente é adotado em Pedro Leopoldo e Sabará, ao definirem altos valores para o tamanho mínimo de lotes, como forma de evitar que seus territórios permaneçam como locus de urbanização de baixa qualidade e ocupação da população de baixa renda.

As estratégias adotadas pelas administrações municipais para reordenação da ocupação e uso do solo denotam, nesse sentido, uma competição intercidades pela população de maior renda. A migração da população de maior renda para áreas anteriormente ocupadas predominantemente pelas camadas populares de baixa renda adiciona um elemento novo à tradicional expansão horizontal da pobreza: "a periferização da riqueza", gerando novos movimentos de expulsão dos mais pobres e, consequentemente, a gentrificação dos espaços.

No mesmo sentido, a análise da dinâmica de ocupação e do uso do solo na RAVN revela a apropriação hierárquica do espaço pelo dinheiro, com consequências na configuração socioespacial da área. Reorganização socioespacial, esta, favorecida, a propósito, pelas ações reguladoras do Poder Público: alterações de zoneamento; flexibilização das normas relativas ao parcelamento, ocupação e uso do solo; elevação do potencial construtivo de parte da circunscrição territorial da RAVN, entre outras medidas.

A instalação dos grandes empreendimentos impactou o mercado da terra no Vetor Norte da RMBH - e, também, da RAVN -, observando-se um significativo aumento nos registros de ITBI, entre os anos de 2000 e 2010. Tal fato reflete não só o aumento do volume de negócios imobiliários (compra/venda), como o aquecimento desse mercado na região, com uma expressiva demanda por casas, apartamentos e lotes, para fins residenciais ou comerciais (Sathler et al., 2011).

Com o fito de obter um retrato dos patamares de valorização dos imóveis residenciais destinados à venda/locação e identificar a ocorrência de especulação imobiliária (renda da terra) na RAVN, realizou-se uma pesquisa na seção de classificados de imóveis do Jornal 
Estado de Minas, um dos mais importantes jornais impressos do Estado. A pesquisa visou mensurar a quantidade de imóveis residenciais colocados à venda/locação, no período de 2001 a 2013, englobando bens de características diversas (casa, casa geminada, apartamento tipo e cobertura, barracão e quitinete).

0 Gráfico 1 demonstra o número de ocorrências ao longo do período e a respectiva evolução dos preços dos imóveis residenciais colocados à venda. De acordo com os dados obtidos, a média de valor dos imóveis residenciais colocados à venda em janeiro de 2001 era de $\mathrm{R} \$ 40.765,43$, e, em julho de 2013, a média de valor dos imóveis passou a ser de $\mathrm{R} \$ 290.205,17$, representado um aumento significativo de, aproximadamente, $712 \%$ no preço dos imóveis.
0 Gráfico 2, por sua vez, demonstra 0 número de ocorrências ao longo do período e a respectiva evolução dos preços dos imóveis residenciais destinados à locação, englobando bens de características diversas (casa, casa geminada, apartamento tipo e cobertura, barracão e quitinete). Acompanhando a evolução dos preços de venda imobiliária, a média de valor dos aluguéis dos imóveis residenciais destinados à locação em janeiro de 2001 foi de $\mathrm{R} \$ 221,36$, e, em julho de 2013, a média dos aluguéis passou a ser de $\mathrm{R} \$ 813,50$, representado um substancial aumento de $368 \%$ no valor da locação.

Interessante observar que, desde 0 ano de 2005 - época do anúncio da instalação da CAMG na RAVN -, os valores dos aluguéis vêm aumentando paulatinamente, e, após o ano de

Gráfico 1 - Evolução dos valores dos imóveis residenciais colocados à venda na RAVN - 2001-2013

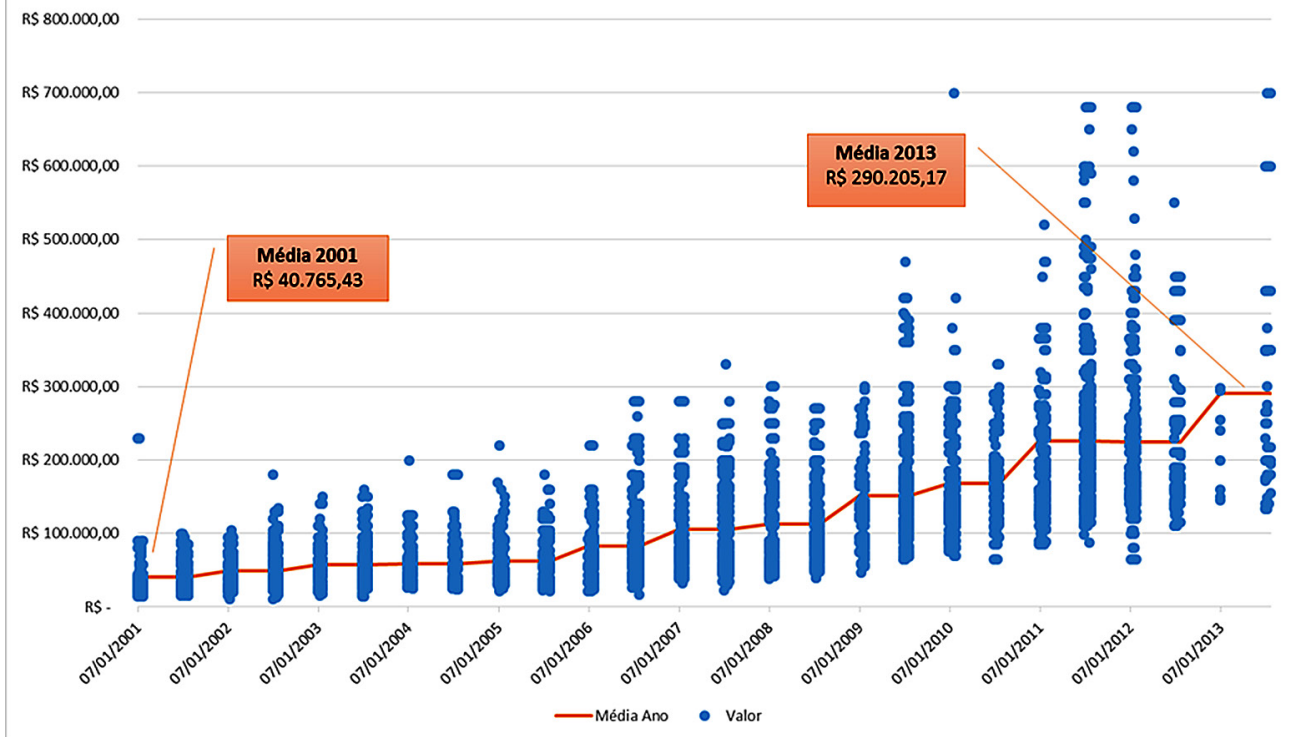

Fonte: dados da pesquisa. 
Gráfico 2 - Evolução dos valores dos imóveis residenciais destinados à locação na RAVN - 2001-2013

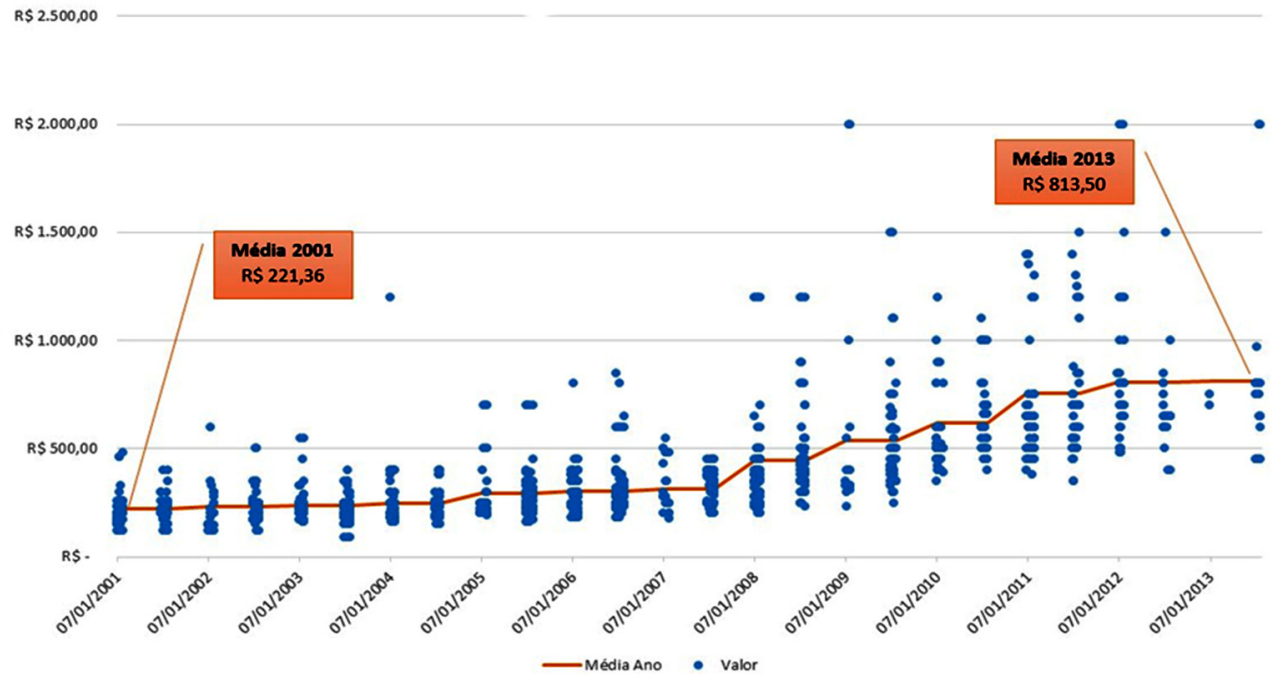

Fonte: dados da pesquisa.

2011, verificam-se ofertas de imóveis com patamares de aluguéis superiores a $\mathrm{R} \$ 1.200,00$, importância superior ao preço médio dos aluguéis de apartamentos praticados em bairros mais nobres - tipificados como de níveis médio e alto pela Fundação Ipead (2011) -, localizados na zona sul do município de Belo Horizonte.

Ressalta-se que a inflação acumulada indicada pelo IGP-M, observada no período 2001-2013, foi de 175\%, enquanto o aumento acumulado do salário mínimo no País foi de $277 \%$. Índices, portanto, inferiores ao percentual de aumento do preço dos imóveis ofertados na RAVN. Salienta-se, ainda, que a gradativa alta no valor dos imóveis coincide com a presença dos novos empreendimentos públicos e privados na região, como a implantação do CAMG e do Shopping Estação $\mathrm{BH}$ (primeiro shopping de grande porte da região) na RAVN (Diniz, 2015).

Atraídas pelo cenário de desenvolvimento e pela melhoria dos patamares de renda e poder de compra da população residente na RAVN, grandes lojas de departamento, de alcance nacional/regional e forte potencial de atração do público consumidor, passaram a atuar nessa regional. Verifica-se, ainda, a transformação do ambiente construído e da paisagem urbana da RAVN, mediante um incremento na infraestrutura urbana, nos equipamentos culturais, de lazer, desporto e transporte; a instalação de uma estação multimodal de transportes (Estação Vilarinho) conjuntamente ao Shopping Estação BH; a oferta de novas 
instituições privadas de ensino superior, de novos centros de saúde públicos e privados, de redes de supermercados, farmácias e de concessionária de veículos, entre outras atividades comerciais que, até então, eram inexistentes ou bastante limitadas na região. Observa-se, assim, que as vantagens locacionais implementadas no Vetor Norte da RMBH tornam a RAVN mais atrativa e, por consequência, mais valorizada (ibid.).

A análise da dinâmica de ocupação e do uso do solo na RAVN, bem como a evolução das tipologias habitacionais e respectivos padrões construtivos, demonstra uma alteração da tipologia de ocupação da área, até então predominantemente horizontalizada e residencial unifamiliar (Tabela 1 ). Constata-se um gradativo processo de verticalização da região, acompanhado de um aumento qualitativo nos padrões construtivos das edificações residenciais e comerciais construídas no período 2001-2013. A alteração da morfologia da área evidencia a atuação do capital imobiliário na produção de mais-valias fundiárias e prenuncia uma ocupação por classes de rendas mais elevadas.

De acordo com os dados cadastrais do IPTU da Smaar de Belo Horizonte, até o ano de 2000, a RAVN apresentava o registro de 42.117 imóveis, dos quais 38.096 (90,45\%) eram residenciais e, dentre estes, $25.078(65,83 \%)$ constituídos por casas e 7.625 (20,02\%) por apartamentos. Gomes (2008) salienta, todavia, que grande parte desses apartamentos foi edificada a partir de 1987 e que a construção de mais de $50 \%$ das casas data de período anterior ao ano de 1981. Nota-se, então, que, após o ano de 2001, o padrão da tipologia construtiva dos

Tabela 1 - Estoque imobiliário da RAVN e respectiva tipologia construtiva

\begin{tabular}{|c|c|c|c|}
\hline \multicolumn{2}{|c|}{ Estoque imobiliário da RAVN (até 2001) } & \multicolumn{2}{|c|}{ Estoque imobiliário da RAVN (2001-2013) } \\
\hline Tipologia & Unidades & Padrão construtivo & Unidades \\
\hline Apartamento & 7.625 & Apartamento & 6.343 \\
\hline Barracão & 5.393 & Barracão & 259 \\
\hline Casa & 25.078 & Casa & 3.139 \\
\hline Loja & 2.989 & Loja & 452 \\
\hline Sala & 206 & Sala & 153 \\
\hline Galpão & 727 & Galpão & 154 \\
\hline Vagas comerciais & 82 & Vagas comerciais & 9 \\
\hline Vagas residenciais & 17 & Vagas rResidenciais & 11 \\
\hline Total de imóveis edificados & 42.117 & Total de imóveis edificados & 10.520 \\
\hline \multicolumn{2}{|c|}{ Total de imóveis na RAVN } & \multicolumn{2}{|c|}{58.733} \\
\hline \multicolumn{2}{|c|}{ Total de imóveis edificados } & \multicolumn{2}{|c|}{52.637} \\
\hline \multicolumn{2}{|c|}{ Total de lotes vagos } & \multicolumn{2}{|c|}{6.096} \\
\hline
\end{tabular}

Fonte: Banco de dados da Smaar - IPTU, PBH, 2014. 
imóveis residenciais localizados na RAVN sofre expressiva alteração, passando a haver uma predominância de construção de condomínios edilícios na região. Entre os anos de 2001 e 2013, houve o acréscimo de 10.520 imóveis nos bairros da região, dos quais 9.741 se destinavam à habitação e, dentre estes, 6.343 $(65,12 \%)$ eram constituídos por apartamentos. Tais números revelam o significativo aumento de unidades condominiais verticalizadas, em detrimento do padrão horizontalizado e unifamiliar das residências adotado majoritariamente até então. Pode-se notar, ainda, uma redução percentual na construção de barracões, quando considerada a totalidade das unidades imobiliárias edificadas no período.

Além da significativa alteração na tipologia dos imóveis edificados na RAVN, os dados cadastrais do IPTU permitem avaliar as características construtivas (tamanho, acabamento, etc.) e os tipos de equipamentos dos imóveis residenciais (garagem, hall privativo, playground, piscina, elevador), bem como dos imóveis comerciais (escada rolante, estacionamento para clientes, garagem) (Tabela 2). A partir de suas características, os imóveis são enquadrados, segundo seu tipo, nos padrões de acabamento: P1, P2, P3, P4 e P5, em que P1 representa a padronização qualitativamente mais baixa e P5 a mais alta.

Observa-se que, até o ano de 2001, os imóveis edificados possuíam padrões construtivos majoritariamente tipificados como de classe P1 $(20,81 \%)$ e P2 (51,51\%), representando, juntos, $72,32 \%$ do total de imóveis residenciais e comerciais edificados. Após 0 ano de 2001, nota-se uma relevante melhora qualitativa dos imóveis construídos na região, com a predominância de edificações padrão P3 $(63,56 \%)$ e um sensível acréscimo de imóveis com alto padrão construtivo, classificados como P4 (0,09\%) e P5 (1,64\%). 0 processo de renovação do parque imobiliário resulta, então, numa considerável diminuição dos imóveis

Tabela 2 - Estoque imobiliário da RAVN e respectivo padrão construtivo

\begin{tabular}{|c|c|c|c|c|c|}
\hline \multicolumn{3}{|c|}{ Estoque imobiliário da RAVN até 2001} & \multicolumn{3}{|c|}{ Estoque imobiliário da RAVN 2001-2013 } \\
\hline Padrão construtivo & Unidades & $\%$ & Padrão construtivo & Unidades & $\%$ \\
\hline P1 & 8.764 & 20,81 & P1 & 1.127 & 10,71 \\
\hline P2 & 21.696 & 51,51 & P2 & 2.525 & 24,00 \\
\hline P3 & 11.219 & 26,64 & P3 & 6.686 & 63,56 \\
\hline P4 & 426 & 1,01 & P4 & 173 & 1,64 \\
\hline P5 & 12 & 0,03 & P5 & 9 & 0,09 \\
\hline Total & 42.117 & 80,01 & Total & 10.520 & 19,99 \\
\hline \multicolumn{3}{|c|}{ Total de imóveis da RAVN } & \multicolumn{3}{|c|}{58.733} \\
\hline \multicolumn{3}{|c|}{ Total de imóveis edificados } & \multicolumn{3}{|c|}{52.637} \\
\hline \multicolumn{3}{|c|}{ Total de lotes vagos } & \multicolumn{3}{|c|}{6.096} \\
\hline
\end{tabular}

Fonte: Banco de dados da Smaar - IPTU, PBH, 2014. 
com padrões construtivos inferiores, de classe P1 $(10,71 \%)$ e P2 (24\%), apesar de a RAVN ser, historicamente, um espaço de ocupação das classes menos favorecidas.

Seguindo as transformações de ordem fundiária e espacial do Vetor Norte, observa-se uma alteração nas características sociodemográficas da RAVN. As significativas alterações nos coeficientes avaliados apontam uma tendência de melhora nos índices de desenvolvimento da RAVN e configuram indícios dos impactos do ajuste estrutural e da reestruturação produtiva da RMBH. Dessa análise, resultaram algumas constatações. Em primeiro lugar, as taxas de analfabetismo apresentaram um relevante processo de redução. Concomitantemente, houve um considerável aumento na população com ensino superior. Sendo certo que pessoas com um nível educacional mais alto têm maior probabilidade de auferirem mais renda (Cangussu, Salvato e Nakabashi, 2010). Em segundo lugar, os resultados referentes ao rendimento mensal da população residente na área pesquisada apresentaram substancial melhora, tanto em relação ao valor máximo da renda domiciliar per capita dos indivíduos pertencentes às parcelas mais pobres, quanto em relação às parcelas mais ricas. Tais resultados refletem algumas das mudanças socioespaciais recentes ocorridas na região.

Assim, em face dos investimentos realizados/programados para o Vetor Norte da $\mathrm{RMBH}$, a dinâmica territorial da RAVN é marcada por uma forte pressão do mercado imobiliário (especulação, aumento do preço da terra), com reflexos na permanência das populações de baixa renda na região. A expansão da demanda efetiva por imóveis e, por conseguinte, a intensa valorização imobiliária nos últimos anos geraram, em contrapartida, a expulsão de parcelas mais vulneráveis da população para periferias mais distantes.

\section{Considerações finais}

Em tempos em que tudo tende à mercantilização e que o valor de troca se sobrepõe ao valor de uso, a apropriação hierárquica do espaço se dá para e pelo dinheiro - favorecida, a propósito, pelo papel de planejador e regulador do Estado -, com consequências na configuração social e no desenvolvimento (desigual) do espaço urbano. Como "máquinas de crescimento" (Logan e Molotch,1987), as cidades - seus espaços e respectivas condições gerais de produção (Lojkine, 1997) - são organizadas de modo a intensificar o uso da terra e, por conseguinte, aumentar os níveis de renda.

Diante da reorganização econômica provocada pela flexibilização e desconcentração espacial da produção, as cidades capitalistas do atual período monopolista ajustam a sua configuração espacial às novas necessidades da economia. Esse movimento de reestruturação urbana e provisão de vantagens locacionais (espaço físico atrativo, infraestrutura, rede de transportes e de serviços) objetiva a inserção e/ou maior competividade das cidades na rede urbana global (Harvey, 1989; Castells e Borja, 1996; Ward, 2004; Ferreira, 2005).

A consolidação do "espaço concebido" (Lefebvre, 2000) do Vetor Norte da RMBH dá-se com o objetivo de garantir a reprodução ampliada do capital, com a oferta de novos empreendimentos/serviços urbanos (instalados ou em via de implantação), decorrentes dos investimentos, públicos e privados, que se 
estruturam a partir de grandes equipamentos como: o Centro Administrativo do Estado de Minas Gerais (CAMG); a "Linha Verde"; a ampliação das funções do Aeroporto Internacional Tancredo Neves (AITN); a implantação do Anel Viário de Contorno Norte, entre outros.

Cabe ressaltar que a valorização imobiliária percebida na RAVN não decorre exclusivamente da presença dos novos empreendimentos, sendo influenciada, também, por fatores conjunturais ligados à própria dinâmica do mercado, ao crescimento do PIB e da renda média das famílias, à intensificação da demanda por terrenos por parte das atividades econômicas, à disponibilidade de crédito e à queda dos rendimentos no mercado financeiro que levou capitais de diversas fontes a buscar o mercado imobiliário para sua reprodução. Não bastasse, a partir de 2004, verificou-se um ambiente político favorável para o aquecimento do mercado imobiliário, diante das políticas de habitação implementadas no País (Sathler et al., 2011).
De todo modo, as intervenções procedidas pelo Poder Público redesenham as estruturas espaciais da RAVN, abrindo novas frentes de investimento e acumulação, com significativa valorização da terra. As melhorias na infraestrutura urbana são acompanhadas de mudanças nas instalações comerciais e na prestação de serviços públicos e privados, atraindo moradores com patamares de renda mais elevados para a região. Em contrapartida, a majoração da "renda da terra" e dos custos de bens e serviços ameaça a permanência dos antigos moradores de baixa renda, explicitando, por conseguinte, a elitização dos espaços.

0 processo de reestruturação, contudo, apresenta-se em seu estágio inicial, tornando-se evidentes a necessidade de mais estudos e a convergência de esforços para determinar sua evolução e especificidades, sobretudo se consideradas as perspectivas de médio e longo prazo dos planos estratégicos de desenvolvimento socioeconômico previstos para o Vetor Norte da RMBH.

\section{[I] https://orcid.org/0000-0001-5396-9999}

Centro Federal de Educação Tecnológica de Minas Gerais, Departamento de Ciências Sociais Aplicadas. Belo Horizonte, MG/Brasil.

lucianodiniz@dcsa.cefetmg.br

\section{[II] https://orcid.org/0000-0003-3927-6787}

Pontifícia Universidade Católica de São Paulo, Departamento de Sociologia. São Paulo, SP/Brasil. mmveras@pucsp.br 


\section{Notas}

(1) Em 2006, a aprovação das leis complementares 88, 89 e 90 estabeleceu o arranjo institucional de gestão metropolitana, definindo os órgãos de gestão e planejamento da RMBH, bem como os instrumentos de gestão - sendo um de planejamento, o PDDI-RMBH, e outro financeiro, o Fundo de Desenvolvimento Metropolitano.

(2) O PMDI estabelece as estratégias do governo para o desenvolvimento socioeconômico integrado e tecnológico do Estado. Lançado em 2000, o PMDI passou por uma série de revisões com o objetivo de consolidar os avanços já alcançados e garantir maior eficácia às ações do governo previstas para o período 2016-2027.

(3) Prevê as ações e os projetos já implantados ou em fase de execução no Vetor Norte da RMBH, visando promover a ampliação da acessibilidade local e regional, o desenvolvimento de empreendimentos de inovação tecnológica, a preservação de ativos ambientais, culturais e científicos e a gestão compartilhada entre os atores envolvidos.

(4) Elaborado pela Jurong Consultants para a Secretaria de Estado de Desenvolvimento Econômico (Sede), o Plano Estrutural tem como objetivo fornecer uma orientação estratégica geral para o desenvolvimento econômico sustentável da RMBH, de médio a longo prazo, estabelecendo diretrizes para usos e ocupação do solo.

(5) Entendidos como aqueles que que "desencadeiam rupturas sobre os espaços físico e social, em suas múltiplas dimensões, e contribuem para a consolidação de mudanças na dinâmica socioespacial, caracterizada por reconfigurações escalares, e efeitos de desenvolvimento desigual na escala local" (Novais et al., 2007, p. 6).

\section{Referências}

ALMEIDA, E. (2009). Avaliação coletiva de imóveis da prefeitura de Belo Horizonte: análise e perspectivas. Monografia de pós-graduação lato sensu. Belo Horizonte, Universidade Gama Filho.

ANDRADE, L. T. (org.) (2009). Como anda Belo Horizonte. Rio de Janeiro, Letra Capital/Observatório das Metrópoles.

ARANTES, O. B. F. (2002). "Uma estratégia fatal: a cultura nas novas gestões urbanas". In: ARANTES, O. B. F.; VAINER, C. B. e MARICATO, E. A cidade do pensamento único: desmanchando consensos. Petrópolis, Vozes.

BORJA, J. e CASTELLS, M. (1997). Local y global: la gestión de las ciudades en la era de la información. Madrid, Taurus.

CALDEIRA, T. P. R. (2000). Cidade de muros: crime, segregação e cidadania em São Paulo. São Paulo, Editora 34/Edusp. 
CANGUSSU, R. C.; SALVATO, M. A. e NAKABASHI, L. (2010). Uma análise do capital humano sobre o nível de renda dos estados brasileiros: MRW versus Mincer. Estud. Econ. São Paulo, v. 40, n. 1, pp. 153-183.

CARDOSO, A. L. (2003). Irregularidade urbanística: questionando algumas hipóteses. Cadernos Metrópole. São Paulo, n. 10, pp. 9-25.

CARVALHO, M. (2004). A caminho de Anhanguera: frente de expansão na produção do espaço urbano no município de São Paulo. Tese de Doutorado. São Paulo, Pontifícia Universidade Católica de São Paulo.

CASTELLS, M. e HALL, P. (1994). Tecnópolis del mundo: la formación de los complejos industriales del siglo XXI. Madrid, Alianza.

CASTELLS, M. e BORJA, J. (1996). As cidades como atores políticos. Novos Estudos CEBRAP. São Paulo, n. 45 , pp. $152-166$.

COMPANS, R. (1999). O paradigma das global cities nas estratégias de desenvolvimento local. Revista Brasileira de Estudos Urbanos e Regionais. Recife, n. 1, pp. 91-114.

COSTA, G. M. (2009). Produção do espaço metropolitano em Belo Horizonte, Brasil: revisitando a economia política da urbanização. In: 12 ENCUENTRO DE GEÓGRAFOS DE AMÉRICA LATINA. Anais. Montevidéu, Easy Planners, pp. 1-14.

COSTA, H. S. M. e MENDONÇA, J. G. (2010). Urbanização recente e disputa pelo espaço na dinâmica imobiliária metropolitana em Belo Horizonte. In: XVII ENCONTRO NACIONAL DE ESTUDOS POPULACIONAIS. Anais. Caxambu, ABEP, pp. 1-17.

COSTA, G. M. e MAGALHÃES, F. N. C. (2011). Processos socioespaciais nas metrópoles de países de industrialização periférica: reflexões sobre a produção do espaço metropolitano de Belo Horizonte, Brasil. Revista Brasileira de Estudos Urbanos e Regionais. Recife, v. 13, n. 1, pp. 9-25.

DINIZ, S. C. e MONTE-MÓR, R. L. (2012). M. A pequena produção popular e solidária como instrumento de fortalecimento e reorganização metropolitana: a visão do PDDI-RMBH. In: XV SEMINÁRIO SOBRE A ECONOMIA MINEIRA. Anais. Diamantina, Cedeplar/UFMG, pp. 1-21.

DINIZ, L. S. (2015). (Re)estruturação urbana e o processo de gentrificação em Venda Nova - Belo Horizonte/MG. Tese de Doutorado. São Paulo, Pontifícia Universidade Católica de São Paulo.

FERREIRA, A. F. (2005). Gestão Estratégica de Cidades e Regiões. Lisboa, Fundação Calouste Gulbenkian.

FIPE - Fundação Instituto de Pesquisas Econômicas (2014). Índice FIPEZAP. Disponível em: www.fipe. org.br. Acesso em: 5 out 2014.

FUNDAÇÃO JOÃO PINHEIRO (2015). Mapa das Regionais Administrativas de Belo Horizonte. Elaborado por Priscilla Costa Pereira. Belo Horizonte.

GOMES, S. M. (2008). “A dinâmica do mercado formal de produção residencial”. In: CALDAS, M. F.; MENDONÇA, J. G. e CARMO, L. N. (coords.). Estudos urbanos Belo Horizonte 2008: transformações recentes na estrutura urbana. Belo Horizonte, Prefeitura de Belo Horizonte.

GOTTDIENER, M. e FEAGIN, J. R. (1989). Uma mudança de paradigma na sociologia urbana. Espaço \& Debates. São Paulo, n. 28, pp. 44-58. 
HARVEY, D. (1989). From managerialism to entrepreneurialism: the transformation in urban governance in late capitalism. Geografiska Annaler, v. 71, n. 1, pp. 3-17.

(2005). A produção capitalista do espaço. São Paulo, Annablume.

(2011). Condição Pós-Moderna: uma pesquisa sobre as origens da mudança cultural. São Paulo, Loyola.

(2013). Os limites do capital. São Paulo, Boitempo.

IBGE - Instituto Brasileiro de Geografia e Estatística (2014). Disponível em: http://www.ibge.gov.br. Acesso em: 2 set 2014.

IPEAD - Fundação Instituto de Pesquisas Econômicas Administrativas e Contábeis de Minas Gerais (2011). Pesquisa do mercado imobiliário em Belo Horizonte: aluguéis. Disponível em: http:// www.ipead.com.br/site/publicacoes/mercadolmobiliario. Acesso em: 3 out 2014.

KAMEL, R. C. A. (2007). Gestão municipal e o processo de organização do espaço urbano da cidade de Belo Horizonte (1894-1960). Belo Horizonte, Fundação João Pinheiro.

KAVARATZIS, M. (2009). What can We Learn from City Marketing Practice? European Spatial Research and Policy, v. 16, n. 1, pp. 41-58.

KOTLER, P.; HAIDER, D. e REIN, I. (1993). Marketing places: attracting investment, industry and tourism to cities, states and nations. Nova York, The Free Press.

LEFEBVRE, H. (1999). A revolução urbana. Belo Horizonte, UFMG.

(2000). La production de l'espace. Paris, Anthropos.

LIMONAD, E. (2011). "Urbanização e organização do espaço na era dos fluxos”. In: SANTOS, M. et al. Território, territórios: ensaios sobre o ordenamento territorial. Rio de Janeiro, Lamparina.

LOGAN, J. R. e MOLOTCH, H. L. (1987). Urban fortunes: the political economy of place. Berkeley-CA, University of California Press.

LOJKINE, J. (1997). O estado capitalista e a questão urbana. São Paulo, Martins Fontes.

MINAS GERAIS (2006). EIA - Estudo de Impacto Ambiental do Centro Administrativo do Estado de Minas Gerais. v. 1. Belo Horizonte, Lume Estratégia Ambiental.

(2007). PMDI 2007-2023 - Estratégia de Desenvolvimento. Belo Horizonte, Secretaria de Estado de Planejamento e Gestão.

(2008). Programa de Desenvolvimento e Gestão da Região Metropolitana de Belo Horizonte Plano de Ações Imediatas para o Vetor Norte. Belo Horizonte, Instituto Horizontes.

(2010). Plano macro-estrutural do Vetor Norte da Região Metropolitana de Belo Horizonte $(\mathrm{RMBH})$. Belo Horizonte, Jurong Consultants Pte.

(2011). Plano Diretor de Desenvolvimento Integrado da Região Metropolitana de Belo Horizonte - PDDI-RMBH - Relatório de Definição das Propostas de Políticas Setoriais, Projetos e Investimentos Prioritários - Sumário Executivo. Belo Horizonte, UFMG - Cedeplar/Face.

(2016). PMDI 2016-2027 - Desenvolvimento Econômico e Social Sustentável de Minas Gerais - Redução das desigualdades sociais e regionais. Belo Horizonte, Secretaria de Estado de Planejamento e Gestão. 
NOVAIS, P.; OLIVEIRA, F. L.; SÁNCHEZ, F. e BIENENSTEIN, G. (2007). Grandes projetos urbanos: panorama da experiência brasileira. In: XII ENCONTRO NACIONAL DA ANPUR. Anais. Belém, Anpur, pp. 1-21.

OLIVEIRA, F. (1979). "Prefácio". In: MARICATO, E. (org.). A produção capitalista da casa (e da cidade) no Brasil industrial. São Paulo, Alfa-Omega.

PREFEITURA MUNICIPAL DE BELO HORIZONTE (2008). Estudo sobre os impactos oriundos de iniciativas localizadas no eixo norte da RMBH e definição de alternativas de desenvolvimento econômico, urbano e social para o município de Belo Horizonte. Relatório Final. Volume III. Avaliação dos Impactos Relativos aos Projetos com Influência na Dinâmica de Desenvolvimento do Município de Belo Horizonte. Belo Horizonte.

(2009). Planejamento estratégico de Belo Horizonte 2030. Belo Horizonte.

(2011). Gestão Compartilhada-mapase estatísticas. Disponívelem: http://gestaocompartilhada. pbh.gov.br/estrutura-territorial/regioes-administrativas. Acesso em: 28 abr 2016.

RODRIGUES, W. (2010). Cidade em transição: nobilitação urbana, estilos de vida e reurbanização em Lisboa. Lisboa, Celta.

ROLNIK, R. (1997). A cidade e a lei: legislação, política urbana e territórios na cidade de São Paulo. São Paulo, Studio Nobel.

SALGUEIRO, T. B. (1998). Cidade pós-moderna: espaço fragmentado. Revista Território. Rio de Janeiro, v. 3, n. 4 , pp. 39-53.

SÁNCHEZ, F. (1999). Políticas urbanas em renovação: uma leitura crítica dos modelos emergentes. Revista Brasileira de Estudos Urbanos e Regionais. Recife, n. 1, pp. 115-132.

SANTOS, M. (1985). A caminho de uma teoria substantiva da urbanização. São Paulo, USP. (2007). O espaço do cidadão. São Paulo, Edusp.

SASSEN, S. (1998). As cidades na economia mundial. São Paulo, Studio Nobel.

SATHLER, D. et al. (2011). O impacto dos grandes empreendimentos no mercado da terra na RMBH: o Vetor Norte em perspectiva. Geografias. Belo Horizonte, v. 7, n. 1.

SAVAGE, M.; WARDE, A. e WARD, K. (2003). Urban sociology, capitalism and modernity. Londres, Palgrave Macmillan.

SINGER, P. (1979). “O uso do solo urbano na economia capitalista”. In: MARICATO, E. (org.). A produção capitalista da casa (e da cidade) no Brasil industrial. São Paulo, Alfa-Omega.

SOUZA, J. e BRITO, F. (2008). Expansão urbana de Belo Horizonte e da RMBH: A mobilidade residencial e o processo de periferização nos anos 80 e 90. In: XIII SEMINÁRIO SOBRE A ECONOMIA MINEIRA. Anais. Diamantina, Cedeplar/UFMG, pp. 1-17.

TOPALOV, C. (1979). La urbanización capitalista: algunos elementos para su análisis. México, Edicol.

UNITED NATIONS, Department of Economic and Social Affairs, Population Division (2015). World Urbanization Prospects: The 2014 Revision. Nova York, United Nations Secretariat, Population Division. 
VAINER, C. B. (2002). "Pátria, empresa e mercadoria: notas sobre a estratégia discursiva do planejamento estratégico urbano". In: ARANTES, O. B. F.; VAINER, C. B. e MARICATO, E. A cidade do pensamento único: desmanchando consensos. Petrópolis, Vozes.

VÉRAS, M. P. B. (2010). Cidade, vulnerabilidade e território. Ponto e vírgula. São Paulo, n. 7.

VILLAÇA, F. (1998). Espaço intraurbano no Brasil. São Paulo, Studio Nobel.

WARD, S. V. (2004). Selling places: the marketing and promotion of towns and cities 1850-2000. Londres, Spon Press.

Texto recebido em 18/jun/2017

Texto aprovado em 27/nov/2018 